\title{
Molecular Evaluation of Resistance to Rifampicin and Isoniazid of Tuberculosis Patients by test "Genotype $®$ MTBDR Plus" in Senegal
}

Babacar Faye ${ }^{1,2,3^{*}}$, Issa Jessika ${ }^{1}$, Mame Cheikh Seck ${ }^{1,4}$, Cheikh Tidiane Ndour ${ }^{5}$, Papa Amadou Lamine Gueye ${ }^{6}$, Fatoumata Ba ${ }^{6}$, Marie Sarr ${ }^{6}$, Michael Grillo ${ }^{7}$, Sharon Reed ${ }^{8}$ and Alioune Dieye ${ }^{3}$

${ }^{1}$ Laboratory of Molecular Biology, Military hospital of Ouakam (HMO), Dakar-Senegal

${ }^{2}$ AIDS Program of the Senegalese Armed Forces, Senegal

${ }^{3}$ Service of Immunology, Department of Pharmacy, Faculty of Medicine, Pharmacy and Odonto- Stomatology of Cheikh Anta Diop University of Dakar, Senegal

${ }^{4}$ Parasitology Unit, Department of Pharmacy, Faculty of Medicine, Pharmacy and Odonto-Stomatology of

Cheikh Anta Diop University of Dakar, Senegal

${ }^{5}$ Service des maladies infectieuses centre national hospitalier de FANN Dakar Senegal

${ }^{6}$ National Program against Tuberculosis (NTP) in Senegal, Senegal

${ }^{7}$ Department of Defense HIVIAIDS Prevention Program (DHAPP), San Diego, California, United States

${ }^{8}$ Microbiology and virology laboratories, University of California, San Diego Center, United States

*Corresponding author: Dr. Babacar Faye, Laboratory of Molecular Biology, Military hospital of Ouakam (HMO), Dakar-Senegal, Tel: +221 77 6341070/+221 33 8601989; E-mail: bab_faye@yahoo.fr

Received date: 30 May 2018; Accepted date: 25 July 2018; Published date: 01 August 2018

Copyright: (c) 2018 Faye B. This is an open-access article distributed under the terms of the creative Commons attribution License, which permits unrestricted use, distribution and reproduction in any medium, provided the original author and source are credited.

\section{Abstract}

Background: Multi Drug Resistant-Tuberculosis (MDR-TB) is a major public health problem in Senegal with less successful treatment of tuberculosis. There were 208 cases of MDR-TB in 2015 surveyed at 31 treatment sites by the National Program against Tuberculosis.

Objectives: The aim of our study is to evaluate the prevalence of Mycobacterium tuberculosis isolates resistant to Rifampicin and Isoniazid and their associated resistance mutations in Senegalese patients.

Materials and methods: MDR-TB was diagnosed by molecular testing (Genotype MTBDRplus Hain Life Science) among sputum samples obtained from 185 Senegalese TB patients and was defined as resistance to both Isoniazid (INH) and Rifampicin (RIF).

Results: The sex-ratio M/W was of 2.2. The median age was 33.5 (8-72 years). Out of 185 positives samples for TB by microscopy, 95\% (174/185) were Mycobacterium tuberculosis complex by Genotype MTBDRplus. The rate of TB-MDR+ in the total study population, treatment naïve, and previously treated was $64.94 \%, 46.25 \%$, and $80.85 \%$, RIF mono-resistance was $10.92 \%, 7.50 \%$, and $13.83 \%$ and INH mono-resistance was $6.32 \%, 8.75 \%$, and $4.26 \%$. Our strains of Mycobacterium tuberculosis have mutations conferring resistance in the $r p o B$, kat $G$ and inhA genes among $75.86 \%, 68.69 \%$, and $13.21 \%$ respectively.

Conclusion: Our results demonstrate a high degree of resistance to Rifampicin and/or Isoniazid among Mycobacterium tuberculosis isolates from patients with a treatment history or contact with a patient with MDR TB which were rapidly detected with the use of Genotype MTBDRplus.

Keywords: Tuberculosis; Mycobacterium; Resistance; Rifampicin; Isoniazid; Genotype ${ }^{\oplus}$ MTBDRplus

\section{Introduction}

Tuberculosis (TB) is a major public health throughout the world. According to WHO 2017 report, there were 10.4 million people who had TB in 2016: $90 \%$ were adults, $10 \%$ were children, $65 \%$ were male and $10 \%$ were people living with HIV in 2016. There were 1.7 million TB deaths among which 0.4 million HIV-positive [1].

In Senegal, there are 20,000 recorded TB cases with a mortality rate of 21 deaths for 100,000 inhabitants. The prevalence and the incidence were estimated at 205 cases per 100,000 inhabitants and 138 new cases per 100,000 inhabitants, respectively [2].

The WHO estimates that early diagnosis and effective therapy of tuberculosis saved 53 million lives between 2000 and 2016, but there are still large gaps in detection and treatment. However, increasing resistance to anti-TB drugs constitutes a major challenge for many $\mathrm{TB}$ treatment programs [3]. The prevalence of multi-drug resistant tuberculosis (MDR-TB) among new cases and previously treated cases has increased everywhere in the world [3,4].

In 2016, there were 600000 new cases with resistance to rifampicin (RIF-TB), of which 490000 had multidrug-resistant TB (MDR-TB) [1]. In Senegal, the external review performed in 2016 by the National Program to Fight against Tuberculosis (PNT) detected 208 MDR-TB 
cases in 2015 at 31 treatment sites. A TB patient is resistant if he is positive at Ziehl Neelsen staining microscope after two months of antiTB treatment.

It is therefore both urgent and important for early diagnosis to identify resistant $\mathrm{TB}$ cases in order to provide appropriate therapy and limit the spread of mycobacterial strains resistant to anti-TB drugs [5]. During the past few years, several molecular techniques have been developed including sequencing, pyrosequesing, real-time PCR, and hybridization to detect the frequency and profile of the mutations associated with drug resistance [6,7]. It is now recommended to use molecular line probes assays (LPA), which include the Genotype ${ }^{\circ}$ MTBDR Plus [8]. Such assays detect MDR-TB, allowing prompt diagnosis of Mycobacterium tuberculosis and detection of the mutations responsible for the resistance to Rifampicin (RIF) and Isoniazid (INH), the first line TB-drugs in Senegal. The LPA uses multiplex PCR for the identification of $\mathrm{M}$. tuberculosis complex (MTBC) and detection of the $r p o B, k a t G$ and inh $A$ genes mutations that confer a resistance to RIF and INH $[6,9]$.

In Senegal, investigation of the frequency and specific mutation profiles associated with anti-TB drug resistance has not previously been done. The aim of our study is to determine the prevalence of antiTB drug resistance (RIF and INH) among 1) treatment naive patients and 2) patients with a history of treatment for TB and to assess the frequency and profile of the mutations associated with $\mathrm{TB}$ drug resistance.

\section{Materials and Methods}

\section{Study design}

This retrospective study was carried out at the Laboratory of Molecular Biology of the Military Hospital of Ouakam (HMO) of Dakar, Senegal. The study did not require ethics approval because the test has already been approved by the WHO for sensitivity testing. The samples used in this study were collected from 2012 to 2015 from TBpositive patients enrolled following microscopic TB diagnosis using the Ziehl Neelsen staining.

The study participants belong to the cohort of the National Program against Tuberculosis (NTP) for the assessment of first line anti-TB drugs resistance to Rifampicin and Isoniazid. Medical history of the patients included report of previous treatment as well as other chronic diseases. The patients were divided into two groups including those naïve to TB treatment $(n=83)$ and those having history of $(n=102)$.

\section{Collection and processing of the sputum samples}

Two sputum samples of 2-10 $\mathrm{ml}$ sputum were collected for each patient for Ziehl Neelsen staining. Collected sputum samples were kept in an icebox and preserved at $-4^{\circ} \mathrm{C}$. $3 \mathrm{ml}$ of each sample were then decontaminated using an equal volume of BBL NALC N-acetyl-Lcysteine $(\mathrm{NaOH} 4 \% 2.9 \%$ Citrate) in a plastic Falcon tube according to the manufacturer's instruction (BBLTM MycroPrepTM Becton Dickson). From the sputum, smears were made on glass slide, fixed and stained using the Ziehl Neelsen method and read at the microscope at X100. Only patients with a positive Ziehl Neelsen test were enrolled in the study.

\section{Line probe assay (LPA)}

LPAs are nitro-cellulose strips which have specific probes attached to them which are complementary to the DNA that is targeted in the specimen. Genotype MTBDRplus is a LPA available for detection of Mycobacterium tuberculosis resistance to rifampicin and Isoniazid. LPA was carried out only on the smear-positive samples.

\section{DNA Extraction}

The extraction of the mycobacterial DNA was carried out using the Genolyse kit (Hain). A volume of $500 \mu \mathrm{L}$ of the decontaminated specimen was centrifuged at $10,000 \mathrm{~g}$ for 15 minutes, and the supernatant was discarded. Then, $100 \mu \mathrm{L}$ of lysis buffer (A-LYS) solution was added to pellet. The suspension was homogenized by vortexing and inactivated by incubation in block heating at $95^{\circ} \mathrm{C}$ for 5 minutes. The neutralizing buffer solution (A-NB) was then added and vortexed. The mixture was centrifuged for $5 \mathrm{mn}$, and the supernatant containing the DNA was recovered and transferred into a conical tube.

\section{DNA amplification}

DNA amplification was performed using Genotype MTBDRplus ${ }^{\circ}$ kit version test 2.0 according to the manufacturer's instructions (Life Hain science, Nehren, GMBH, Germany). The reactional medium for the PCR was composed by a mix of nucleotidic primer and amplification probes in $\mathrm{MgCl}_{2}$, sterile water, and Taq polymerase. The amplification consisted of $15 \mathrm{mn}$ of denaturation to $95^{\circ} \mathrm{C}$, followed by 10 cycles of denaturation at $95^{\circ} \mathrm{C}$ during $30 \mathrm{~s}$ and primers annealing at $65^{\circ} \mathrm{C}$ during $2 \mathrm{mn}$. This was followed by 20 cycles of denaturation at $95^{\circ} \mathrm{C}$ during $25 \mathrm{~s}$, at annealing at $50^{\circ} \mathrm{C}$ during $40 \mathrm{~s}$, at $70^{\circ} \mathrm{C}$ during 40 seconds, and a final extension at $70^{\circ} \mathrm{C}$ during $8 \mathrm{mn}$.

\section{Revelation}

The PCR results were displayed by hybridization and revelation using a twincubator. The revelation method used the MTBDRplus version2 (Hain) with covered strips of highly specific probes, which are selected complementary to the amplified nucleic acid sequences. After hybridization and washing, the bands were fixed on paper, and the results were interpreted. The Genotype ${ }^{\oplus}$ MTBDRplus band contains 27 probes, including 6 six controls (combined, amplification, complexes, $r p o B$, katG and inhA of Mycobacterium tuberculosis, for PCR validation. For the detection of resistance to RIF, 8 eight wild-type (WT) probes (probes WT1 to with WT8) included the regions area of the amino acids corresponding to 500 to 531 of the coding $r p o B$ gene. Four probes (probes $r p o B$ D516V, $r p o B$ H526Y, $r p o B$ H526D, and $r p o B \mathrm{~S} 531 \mathrm{~L}$ ) targeted the mutations specifically conferring a resistance to RIF. For the detection of resistance to INH, a probe covered the area of the codon 315 of wild-type of katG gene (WT), while two other probes (katG MUT1 and MUT2) were designed to detect S315T1 and S315T2 mutations on the katG gene. Finally, for the detection of resistance to INH related to the translation of the inh $A$ genes, two probes were used to detect the wild type WT1 and WT2 bands and 4 other probes detected the band of MUT1, MUT2, MUT3A and MUT3B mutations.

The absence of one or more wild-type probe(s) and/or the presence of one or more mutant probe (s) were indicative of a resistant strain (Figure 1). 
Citation: Faye B, Jessika I, Seck MC, Ndour CT, Lamine Gueye PA, et al. (2018) Molecular Evaluation of Resistance to Rifampicin and Isoniazid of Tuberculosis Patients by test "Genotype $®$ MTBDR Plus" in Senegal. J Trop Dis 6: 281. doi:10.4172/2329-891X.1000281

Page 3 of 8

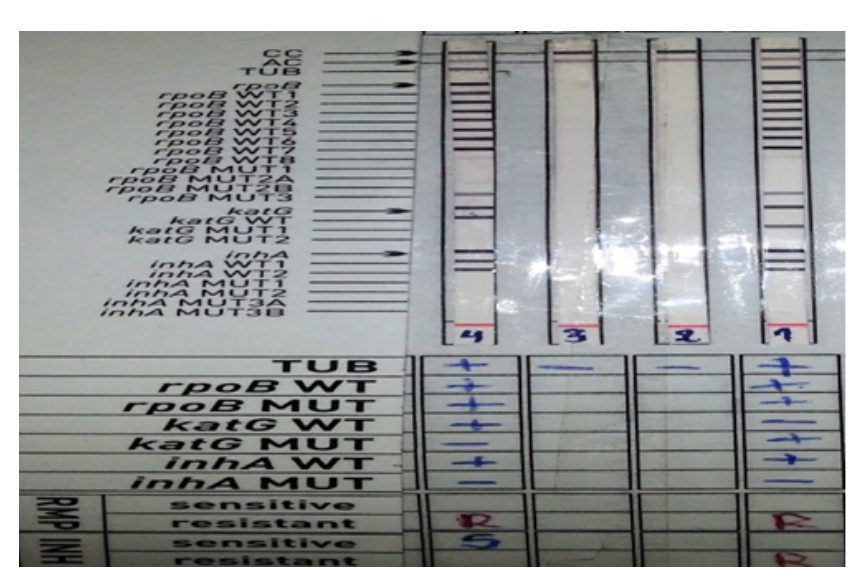

Figure 1: MTBDRplus interpretation Interprétation of Genotype MTBDRplus results (cf revelation in material and method): Patient 1 is multi-resistant because of the presence of the MUT3 band in the $r p o B$ gene, the absence of WT band, and the presence of MUT1band in the kat $G$ gene showing a resistance to both RIF and INH. Patients 2 and 3 are not Mycobacterium tuberculosis because the control TUB band does not appear. Patient 4 is RIF monoresistant because of the presence MUT3 band in $r p o B$ gene.

\section{Statiscal analysis}

The data were obtained from the computerized records and file review. Descriptive analysis was done for demographic, clinical and mutation profiles features. Data analysis was performed using Statistical Package for the Social Sciences version 20 (SPSS Inc, Chicago, IL, USA). Frequencies were obtained for categorical clinical variables. Median and interquartile range were determined for continuous variables. Categorical variables were compared using Fisher's exact test, and continuous variables were compared using the Mann-Whitney U-test. $\mathrm{P}<0.05$ was considered statistically significant.

\section{Results}

\section{The study population}

Among the patients, male gender represented $68.65 \%$ compared to $31.35 \%$ females, resulting in a sex- ratio (man/women) of 2.19 . According to the history of the treatment, the tuberculosis patients were classified as treatment naïve (44.86\%) and previously treated (55.13\%) (Table $1 ; \mathrm{P}<0.001)$ A certain number of treated naïve patients were sent to the laboratory because they have been initially in contact with MDR-TB patients. Previously treated patients are in priority composed of: treatment failures, relapses and retreatment after abandonment of the first treatment.

\begin{tabular}{|l|l|l|l|l|l|l|}
\hline & $\begin{array}{l}\text { Treatment } \\
\text { Naïve }\end{array}$ & $\begin{array}{l}\text { Previously } \\
\text { Treated }\end{array}$ & & Total & \\
\hline Sex & $\mathbf{N}$ & $\%$ & $\mathbf{N}$ & $\%$ & $\mathbf{N}$ & $\%$ \\
\hline Men & 52 & 28.11 & 75 & 40.54 & 127 & 68.65 \\
\hline Women & 31 & 16.76 & 27 & 14.59 & 58 & 31.35 \\
\hline Total & 83 & 44.87 & 102 & 55.13 & 185 & 100 \\
\hline
\end{tabular}

Table1: Distribution according to sex and treatment status of patients.

The median age of the patients was 33.5 (range between 8-72 years). In the study population, the highest frequency was found in the age group of $21-30$ years with $43.78 \%$ (81/185) followed by age group $31-40$ years $24.32 \%$ (45/185). When compared by gender, the same age groups were the most impacted, with $39.66 \%$ (23/185) and $22.41 \%$ (13/185) among women, and $45.67 \%(58 / 185)$ and $25.20 \%(32 / 185)$ among men. (Table 2; $\mathrm{P}=0.26$ ) Out of $185 \mathrm{TBM}+$ samples, $94 \%$ (174/185) were confirmed as being Mycobacterium tuberculosis Complex by Genotype MTBDRplus test (absence of the TUB band, Figure 1, patient 2 and 3 for example).

\begin{tabular}{|l|l|l|l|l|l|l|}
\hline $\begin{array}{l}\text { Group of } \\
\text { age }\end{array}$ & \multicolumn{2}{|l|}{ Women } & \multicolumn{2}{l|}{ Men } & \multicolumn{2}{l|}{ Total } \\
\hline year & N & $\%$ & N & $\%$ & N & $\%$ \\
\hline $0-10$ & 1 & 1.72 & 0 & 0 & 1 & 0.54 \\
\hline $11-20$ & 8 & 13.72 & 6 & 4.72 & 14 & 7.58 \\
\hline $21-30$ & 23 & 39.66 & 58 & 45.67 & 81 & 43.78 \\
\hline $31-40$ & 13 & 22.41 & 32 & 25.2 & 45 & 24.32 \\
\hline $41-50$ & 6 & 10.34 & 15 & 11.81 & 21 & 11.35 \\
\hline $51-60$ & 7 & 12.06 & 11 & 8.66 & 18 & 9.73 \\
\hline $61-70$ & 0 & 0 & 4 & 3.15 & 4 & 2.16 \\
\hline $71-80$ & 0 & 0 & 1 & 0.79 & 1 & 0.54 \\
\hline Sub total & 58 & 31.35 & 127 & 68.65 & 185 & 100 \\
\hline
\end{tabular}

Table 2: Infection rate relative to age and genderDistribution of resistance.

\section{Distribution of resistance}

Resistance to RIF and INH of the 174 isolates belonging to Mycobacterium tuberculosis complex, 17.82\% (31/174) were sensitive to both RIF and INH. Specifically, 37.59\% (30/80) of the strains of treatment naïve patients and $1.06 \%(1 / 94)$ of the previously treated patients were sensitive to both RIF and INH (Table 3; $\mathrm{P}<0.001$ ).

\begin{tabular}{|c|c|c|c|c|c|c|c|c|c|c|}
\hline \multirow[b]{2}{*}{ Types of patients } & \multicolumn{2}{|c|}{ Sensitive } & \multicolumn{4}{|c|}{ Mono-resistant } & \multicolumn{2}{|c|}{ MDR (RIF+INH) } & \multicolumn{2}{|c|}{ Global } \\
\hline & $\mathrm{N}$ & $\%$ & NRIF & $\%$ & $\mathrm{NINH}$ & $\%$ & $\mathrm{~N}$ & $\%$ & & $\%$ \\
\hline Treatment naive & 30 & 37.5 & 6 & 7.5 & 7 & 8.75 & 37 & 46.25 & 80 & 45.98 \\
\hline Previously Treated & 1 & 1.06 & 13 & 13.83 & 4 & 4.26 & 76 & 80.85 & 94 & 54.02 \\
\hline
\end{tabular}


Citation: Faye B, Jessika I, Seck MC, Ndour CT, Lamine Gueye PA, et al. (2018) Molecular Evaluation of Resistance to Rifampicin and Isoniazid of Tuberculosis Patients by test "Genotype $®$ MTBDR Plus" in Senegal. J Trop Dis 6: 281. doi:10.4172/2329-891X.1000281

Page 4 of 8

\begin{tabular}{|l|l|l|l|l|l|l|l|l|l|l|}
\hline Total & 31 & 17.82 & 19 & 10.92 & 11 & 6.32 & 113 & 64.94 & 174 & 100 \\
\hline
\end{tabular}

Table 3: Results of the molecular test MTBDR plus Genotype of sensitivity to Rifampicin and Isoniazid of the strains of Mycobacterium tuberculosis.

RIF mono-resistance was $10.92 \%$ (19/174) among the overall study population, $7.5 \%(6 / 80)$ in the treatment naïve patients, and $13.83 \%$ $(13 / 94)$ in previously treated patients (Table 3; $\mathrm{P}<0.001$ ).

INH mono-resistance was $6.32 \%(11 / 174)$ among the whole study population, $4.26 \%(4 / 94)$ in the treatment naïve patients, and $8.75 \%$ $(7 / 80)$ in previously treated patients. (Table $3 ; \mathrm{P}<0.001$ )

Multi-resistance to both RIF and IHN (MDR-TB) was observed among $64.94 \%(113 / 174)$ of all the samples tested and belonging to
Mycobacterium tuberculosis complex (MTC). MDR-TB was observed among $46.25 \%(37 / 80)$ of treatment naïve patients and $80.85 \%(76 / 94)$ of and previously treated patients (Table $3 ; \mathrm{P}<0.001$ ).

\section{Mutation profile (Table 4)}

According to the Genotype MTBDRplus (Figure 1), a Mycobacterium tuberculosis strain is resistant when there is absence of the Wild Type bands (WT) or presence of the mutation bands (MUT).

\begin{tabular}{|c|c|c|c|c|c|c|}
\hline \multicolumn{7}{|l|}{ rров (132) } \\
\hline Stip- band & Mutation & $\begin{array}{l}\text { Monoresistant } \\
\operatorname{RIF}(n=19)\end{array}$ & $\%$ & $\begin{array}{l}\text { MDR } \\
(n=113)\end{array}$ & $\%$ & ID Patients \\
\hline \multirow{8}{*}{ Absence } & WT1 & 0 & 3 & 3 & 2.65 & $1274 / 13,693 / 14,1637 / 13$ \\
\hline & WT2 & 5 & 26.32 & 3 & 2.65 & $1186 / 13^{*}, 1161 / 13,6065^{*} / 14,2927 / 14^{*}, 2822 / 14,267 / 14^{*}, 194 / 13^{*}, 170 / 13$ \\
\hline & WT3 & 2 & 10.53 & 18 & 15.93 & $\begin{array}{l}\text { 6101/14, 5119/14, 2837/14* 2843/14, 2653/15, 3739/15, 2216/14*, 1362/14, } \\
005 / 14,885 / 467 / 13,170 / 13,23 / 13,2228 / 13,2091 / 13,1637 / 13,1538 / 13 \text {, } \\
1402 / 13,1161 / 13,1141 / 13\end{array}$ \\
\hline & WT4 & 1 & 5.26 & 15 & 13.27 & $\begin{array}{l}1402 / 13,1538 / 13,1141 / 13,6101 / 14,5119 / 14,2843 / 14,2653 / 15,3739 / 15, \\
005 / 14,885 / 13,467 / 13,294 / 13^{*}, 23 / 13,2228 / 13,2091 / 13,1402 / 13\end{array}$ \\
\hline & WT5 & 0 & 0 & 3 & 2.65 & $407 / 14,005 / 14,2130 / 13$ \\
\hline & WT6 & 0 & 0 & 4 & 3.54 & $407 / 14,2130 / 13,2024 / 13,1637 / 13$ \\
\hline & WT7 & 0 & 0 & 15 & 13.27 & $\begin{array}{l}2888 / 14,1020 / 15,2724 / 14,2457 / 14,2180 / 14,1859 / 14,1546 / 14,438 / 14, \\
929 / 14,886 / 13,671 / 13,154 / 13,71 / 13,2029 / 13,745 / 13\end{array}$ \\
\hline & WT8 & 12 & 63.5 & 61 & 53.98 & 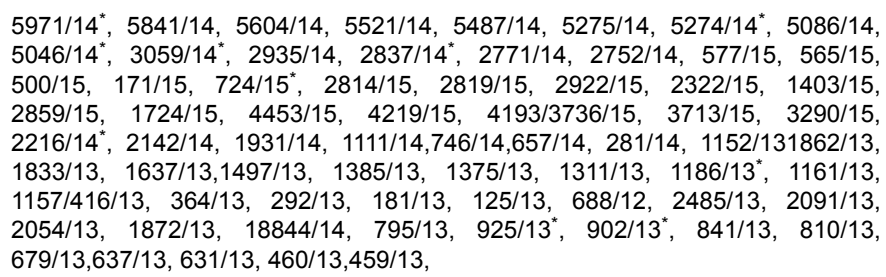 \\
\hline \multirow{5}{*}{ Presence } & MUT1= D516V & 0 & 0 & 2 & 1.77 & $620 / 15,788 / 12$ \\
\hline & MUT2A=H526Y & 0 & 0 & 3 & 2.65 & $664 / 15,464 / 14,788 / 12$ \\
\hline & MUT2A=H526Y & 0 & 0 & 2 & 1.77 & $2545 / 14,1103 / 14$ \\
\hline & \multirow{2}{*}{ MUT3=S531L } & \multirow{2}{*}{1} & \multirow{2}{*}{5.26} & \multirow{2}{*}{11} & \multirow{2}{*}{9.73} & $2319 / 13,2262 / 13$ \\
\hline & & & & & & $2319 / 13,2262 / 13$ \\
\hline \multicolumn{7}{|c|}{ KatG $(11+113=124)$} \\
\hline Stip band & Mutation & $\begin{array}{l}\text { Monoresistant } \\
\text { INH }(n=11)\end{array}$ & $\%$ & $\begin{array}{l}\text { MDR } \\
(n=113)\end{array}$ & $\%$ & ID Patients \\
\hline Absence & WT & 5 & 45.45 & 105 & 92.92 & $\begin{array}{lcccc}6088^{*} / 14, \quad 6101 / 14, \quad 5841 / 14, \quad 5604 / 14, & 5521 / 14,5487 / 14, & 5275 / 14, \\
511,5086 / 14,2935 / 14,2888 / 14,2843 / 14,2771 / 14, & 2752 / 14,577 / 15,565 / 15,50, \\
171 / 15,1009 / 15,2814 / 15,2819 / 15,2922 / 15,2322 / 15, & 1403 / 15, \\
1020 / 15,2859 / 15,172171 / 15,1009 / 15,2814 / 15,2819 / 15,2922 / 15,2322 / 15, \\
1403 / 15,1020 / 15,2859 / 15,172,2653 / 15,2545 / 14,2487 / 14^{*}, 2457 / 14,2180 / 14,\end{array}$ \\
\hline
\end{tabular}




\begin{tabular}{|l|l|l|l|l|l|}
\hline & & & & & $\begin{array}{l}2142 / 14,1859 / 14,1931 / 14,1719 / 14,1546 / 14,1364453 / 15,4219 / 15,3739 / 15, \\
3736 / 15,3713 / 15,3290 / 15,276273^{*}, 270189^{*}, 272\end{array}$ \\
\hline
\end{tabular}

Table 4: Types of mutation and their frequencies in the resistance of the Mycobacterium tuberculosis strains to Rifampicin (RIF) and Isoniazid (IHN). This table shows WT or MUT bands present at $R p o B, K a t G$ and inhA genes. Mutations are represented on the left and on the right side the patient's numbers who have these mutations. (NB: 1) “*” represents the strains that are mono-resistant's in Rifampicin (RIF) or Isoniazid (INH). (2) 2822/14: 2822 is the patient number; and 14 is the year of the sputum samples.

Of the 174 samples of Mycobacterium tuberculosis, $75.86 \%$ $(132 / 174 ; \quad \mathrm{P}=0.013)$ have $r p o B$ gene mutations conferring RIF resistance (MDR-TB and/or RIF mono-resistant), 68.96\% (120/174) $(\mathrm{P}<0.001)$ have $k a t G$ gene mutations, and $13.21 \%(23 / 174)(\mathrm{P}=0,025)$ have inhA gene mutations, conferring INH resistance (MDR-TB and/or INH-mono-resistant) (Table 4).

RIF mono-resistance: Among the 10.92\% (N=19/174) of the RIF mono-resistant isolates, the most frequent mutations were the absence of bands WT8 in $63.5 \%(12 / 19)$, WT2 in $26.32 \%(5 / 19)$, and WT3 in $10.53 \%(2 / 19)$ on the $r p o B$ gene (Table $4 ; \mathrm{P}=0.013$ )

INH mono-resistance: Among the 6.32\% $(\mathrm{N}=11 / 174)$ of isolates INH mono-resistant, the most frequent mutations were the absence of WT band in $45.45 \%(5 / 11)$, and the presence of the MUT1 (D516V) band in $36.36 \%(4 / 11)$ on the gene $k a t G$ (Table $4 ; \mathrm{P}<0.001$ ). The mutations of INH mono-resistance related to the inh $A$ gene were rare.

Multi-resistance RIF and INH (MDR-TB): For the MDR-TB, $64.94 \%(\mathrm{~N}=113 / 174)$, i.e. the samples having a both resistance to RIF and INH, the most frequent mutations were the absence of bands WT8 in $53.98 \%(61 / 113)$, WT3 in $15.93 \%(18 / 113)$, WT4 in $13.27 \%$ $(15 / 113)$, WT7 in $13.27 \%(15 / 113)$, and the presence of the MUT3 band in $9.73 \%(11 / 113)$ on the $r p o B$ gene (Table 4 ; $\mathrm{P}<0.013)$. The mutations on the kat $G$ gene of MDR-TB samples were mainly the absence of WT band in $92.92 \%(105 / 113)$ and the presence of MUT1 $(\mathrm{S} 315 \mathrm{~T} 1)$ in $4.42 \%(5 / 113)(; \mathrm{P}<0.001)$.

For the inh $A$ gene, the mutations were related to the absence of WT1 in $7.08 \%(8 / 113)$ and of WT2 in $8.85 \%(10 / 113)$ (Table 4; $\mathrm{P}<0.025)$.

\section{Discussion}

In Senegal, the efforts to control tuberculosis are focused on the detection of the new cases to initiate early treatment. Initial tuberculosis therapy uses mainly the first line anti-TB drugs RIF and INH along with Pyrazinamide and Ethambutol. Incomplete treatment because of poor adherence can lead to resistance to anti-TB drugs and requires the use of second line drugs. The increase of MDR-TB worldwide, particularly in low-income countries requires the use of testing for prompt diagnosis and detection of mutations in order to limit the therapeutic failures and the propagation of drug resistant mycobacterial strains.

In the present study, we used the Genotype MTDRplus test to determine the frequency and the profile of $r p o B$, $k a t G$ and inh $A$ genes mutations among TB patients. The Genotype MTDRplus test has a sensitivity of $95.8 \%$ for the detection of RIF resistance and sensitivity $96 \%$ for the detection of INH resistance $[6,10-17]$.

Our results show that the infection rate of tuberculosis was higher in men compared to women $(\mathrm{P}=0.15)$. This result is similar to the ratios found in India [18] and South India [19]. This ratio (2.19) is however higher than that found in certain countries of Africa which is equal to 1 [20], and to the worldwide ratio of 1.7.

Of 185 TB patients, $68.11 \%$ were young with an age ranging between 20 and 40 years in both sexes. Similar results were noted in India with $63.3 \%$ [18]. These observations on the gender/age of the TBinfected populations allow a better targeting in the tuberculosis prevention activities of the national program [21].

The bacteriological diagnosis of tuberculosis is first done by the identification of acid fast bacilli (AFB) by microscopic examination, which does not allow differentiation of Mycobacterium tuberculosis complex (MCTB) from other mycobacteria atypical [22]. Among the 185 positive strains by Ziehl- Nielsen staining, $94 \%$ belonged to the complex tuberculosis (MTBC) according to the criteria of the Genotype ${ }^{\circ}$ MTDRplus test. This result is similar to those previously recorded in Zambia (93.3\%) [23] and India (90.76\%) [18].

Our study showed that the RIF mono-resistance was $10.92 \%$, $13.83 \%$ and $7.5 \%$ respectively for the general population, treatment naïve, and previously treated patients. Our results for the treatment naive $(13.83 \%)$ is higher than those found by several studies in India with figures going from $0.5 \%$ to $6.8 \%$ [24-29], $6.6 \%$ in China, $1.5 \%$ in Uganda, $1.6 \%$ in Germany, and $2.6 \%$ in Australia [30]. On the other hand, our results are lower than those found in other studies performed in India 19.42\%, [18], 23.5\% in Saudi Arabia and 50\% in Bangladesh [31,32]. RIF mono-resistance in the previously treated patients is lower than that reported in India, 28.2\% with Jaipur [27] 74.4\% with Mumbai [33] and 33.7\% with New Delhi [25], 46.1\% in Ethiopia [34], 29.7\% in China [30], 62.5\% with Ouzbekistan [35], and $80 \%$ in Bangladesh [32]. However RIF mono-resistance at these patients was described similar to Uganda $13.4 \%$, and low in Germany 7.7\% and in Sri Lanka 2.6\% [30].

Our results show an INH mono-resistance of $6.32 \%, 8.75 \%$ and $4.26 \%$ respectively on the level of the general population of study, treatment naïve and previously treated patients. A study in Ethiopia [35] found a similar result of $6.3 \%$ to that of the general study population. Contrary to the other types of resistance, the INH-monoresistance is lower among previously treated patients. Among treatment naive patients, our results were higher compared to those found in Uganda (5.8\%) and Germany (7.1\%), but similar to that of Australia (8.9\%) [30], while lower than those found in Bangladesh 54.5\% [32], Saudi Arabia 33.8\% [31], and India 21.35\% [18]. For the previously treated patients, our results reveal an INH mono-resistance lower than those found in India 39.7\%, [27], Ethiopia 56.1\%, Bangladesh $82.6 \%$, China $38 \%$, Germany $15.4 \%$, Uganda $20 \%$, Australia 29.2\%, and Sri Lanka 5.3\% [30].

Resistance to both RIF and INH (MDR-TB) was 64.94\%, 46.25\% and $80.85 \%$ respectively in the overall study population, treatment naïve, and previously treated patients. 
Among naive patients, the level of MDR was higher than that described in India 24\% [36], Bangladesh 40.9\% [32], and Saudi Arabia $20.6 \%$ [31]. This high rate of MDR was likely related to the recruitment of the treatment naive patients who were in contact with MDR patients.

Our study shows a very high MDR resistance rate among previously treated patients of $80.5 \%$. A similar rate was found in studies from Bangladesh for RIF and INH resistance with $80 \%$ [32], $82.6 \%$ respectively [30]. Our results were higher than described in New Delhi $33.7 \%$ [25], in Mumbai 41\% [36], Ethiopia 36.3\% [37], and Burkina Faso 55.5\% [38].

Our high MDR-TB rate is likely explained by testing patients who were strongly suspected of MDR-TB, had treatment failures, relapses and retreatment after abandonment of the first treatment. According to the WHO-2015 report on tuberculosis, Senegal recorded 887 relapses of pulmonary tuberculosis of which $73.6 \%$ were confirmed bacteriologically and $16.4 \%$ clinically diagnosed (MDR) [2]. These findings justify the importance of the early detection of resistance to anti-TB drugs.

For the first time in Senegal, the profiles of resistance mutations genes of Mycobacterium tuberculosis are documented.

RIF inhibits the transcription of mRNA by blocking the beta unit encoded by polymerase $r p o B$ genes of Mycobacterium tuberculosis [39]. RMP resistance is related to mutations in a restricted area of this gene $r p o B$. In the Genotype MTDR plus test, RIF resistance is related to the absence of one or more bands WT (WT1 to WT8) and/or the presence of the mutation band (MUT1, MUT2A, MUT2B and MUT3) in area 500-531 of the $r p o B$ gene (Figure 2).

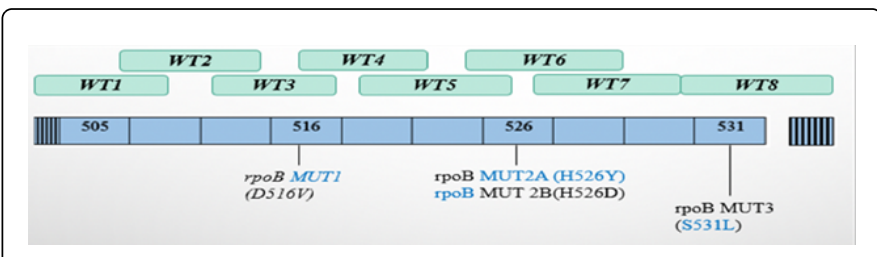

Figure 2: Area of the gene $r p o B$ and its mutations of resistance to RIF.

In our study, $75.86 \%$ of the strains of the MTC have mutation of $r p o B$ genes. Our results show that the most frequent mutations are the absence of bands WT8 (55.30\%), WT3 (15.15\%), WT4 (12.12\%), WT7 (11.36\%), and the presence of mutation MUT3 in 9.09\% (Table 4). The other types of mutations of this gene are negligible. Studies of the RIF resistance on Mycobacterium tuberculosis strains showed that the frequent mutation is MUT3 with $88.6 \%$ in South Africa, [10] and in India $62.2 \%[7,18]$.

INH is activated by the catalase-peroxidase encoded by $K a t G$ gene. The INH resistance of Mycobacterium tuberculosis is associated with mutations in the $\operatorname{kat} G$ and inh $A$ genes [10,40]. Our results show that $71.26 \%(124 / 174)$ of isolates of Mycobacterium tuberculosis are INH resistant (MDR+ INH- monorésistant) with $68.96 \%$ with mutations of $k a t G$ and $13.21 \%$ of mutations of $i n h A$ genes (Table 4). Other studies showed mutations of $k a t G$ of $81.8 \%$ [41] and from 50 to $100 \%$ [9] with mutations of inh $A$ genes.

The most frequent mutations were the absence of WT (88.71\%) and the presence of MUT1 (S315T1) with 7.26\% at the katG gene. For the inh $A$ gene, the absence of WT1 and WT2 were noted at $7.26 \%$ and $8.06 \%$ respectively.

Other studies show a higher frequency of MUT1 mutation $74.32 \%$ [18] and 93.3\% [7] in India. Most often, we found that our Mycobacterium tuberculosis (MTC) strains with mutations of RIF and INH had absent WT bands rather than the presence of MUT bands. Because the patients included in the study had a therapeutic failure, relapse, or contact with MDR-TB patients, our population was enriched for MDR strains.

Since Genotype MTDR plus test has a reported sensitivity of $95.8 \%$ for the detection of RIF resistance and of $96 \%$ for the detection of INH resistance [6,10-17], our high prevalence is likely to be accurate and additional mutations that may not hybridize with the MUT bands may be present. The clinical exams of the patients are in favor of the liability of our results. To answer this question in a rigorous way, it will be necessary to conduct a phenotypic study of sensitivity to Rifampicin and isoniazid of the Mycobacterium tuberculosis strains from cultures followed by sequencing of the $r p o B, k a t G$ and $i n h A$ genes.

\section{Conclusion}

Our data have shown that MDR-TB is higher among patients with antecedents of treatment compared to new cases. The mono-resistance in Rifampicin and Isoniazid is much less common than MDR-TB.

The MDR-TB presented more mutations on the $r p o B$ gene than mutations on the kat $G$ gene level. The resistance mutations of Mycobacterium tuberculosis strains were more related to the absence of WT bands than with the presence of the MUT bands. Further studies of the phenotypic sensitivity of cultures and sequence analysis of the $r p o B, k a t G$ and inhA genes in Senegal and other countries will better define the profiles of mutation resistances to anti-TB drugs and help evaluate the reliability of the molecular testing.

\section{Acknowledgments}

The authors thank the National Program against Tuberculosis in Senegal (NTP) to have placed at our disposal necessary reagents, and the Department of Defense HIV/AIDS Prevention Program (DHAPP) for the support in material/equipment of molecular biology.

\section{Author's contribution}

Conceived and designed the experiments: Babacar Faye, Alioune Dieye.

Performed the experiments: Babacar Faye, Issa Jessika.

Analyzed the data: Cheikh Tidiane Ndour, Babacar Faye, Issa Jessika.

Contributed for reagents/materials/analysis tools: Papa Amadou Lamine Gueye, Fatoumata Ba, Marie Sarr.

Wrote the paper: Babacar Faye, Alioune Dieye, Mame Cheikh Seck. Conceived and designed the study: Babacar Faye Alioune Dieye.

Reviewed critically the manuscript for important intellectual content: Michael Grillo, Sharon Reed.

Approved the final version to be published: Alioune Dieye, Cheikh Tidiane Ndour.

Conflicts of Interest: There are no conflicts of interest. 


\section{References}

1. World Health Organization (2017) Global Tuberculosis report.

2. World Health Organization (2015) Total Tuberculosis Carry forward.

3. World Health Organization (2013) Total the WHO/IUATLD Project one Anti tuberculosis Drug Resistance Monitoring. Anti-tuberculosis Drug Resistance in the World. Total Fourth Carryforward. Geneva, Switzerland.

4. Sharma SK, Kumar S, Saha PK, George N, Arora SK, et al. (2011)Prevalence of multidrug-resistant tuberculosis among category II pulmonary tuberculosis patients. Indian J Med Res 133:312-315.

5. Parsons LM, Somoskovi A, Urbanczik R, Salfinger M (2004) Laboratory resistant diagnosis aspects of drug tuberculosis. Front Biosci 9:2086-2105.

6. Hillemann D, Weizenegger M, Kubica T, Richter E, Niemann S (2005) Use of genotype MTBDR assay for rapid detection of rifampicin and isoniazid resistance in Mycobacterium tuberculosis complex isolates. J Clin Microbial 43:3699-3703.

7. Maurya AK, Singh AK, Kant S, Umrao J, Kumar M, et al. (2013) Uses of Genotype $^{\circ}$ MTBDRplus assay to assess drug resistance and mutation patterns off multidrug-resistant tuberculosis isolates in northern India. Indian J of Med Microbiol 2013-2036.

8. World Health Organization: Policy statement. Molecular Line Honest Assays for Rapid Screening of patient resistant at risk off multidrug tuberculosis (MDR-TB) 2008.

9. Huyen MN, Tiemersma EW, Lan NT, Cobelens FG, Dung NH, et al. (2010) Validation of the GenoType MTBDRplus assay for diagnosis off multidrug resistant tuberculosis in South Vietnam. BMC infectious diseases 10: 1 .

10. Barnard M, Albert H, Coetzee G, O' Brien R, Bosman ME, et.al (2008) Rapid molecular multidrug- resistant screening for tuberculosis in has public high-volume health laboratory in South Africa. Am J Respir Crit Care Med 177:787 -792.

11. Brossier F, Veziris NR, Truffot-Pernot C, Jarlier V, Sougakoff W (2006) Performance of the honest genotype MTBDR line assay for detection off resistance to rifampin and isoniazid in strains of Mycobacterium tuberculosis with low- and high-level resistance. J Clin Microbiol 44: 3659-3664.

12. Cavusoglu C, Turhan A, Akinci P, Soyler I (2006) Evaluation off the Genotype MTBDR assay for rapid detection of rifampin and isoniazid resistance in Mycobacterium tuberculosis isolates. J Clin Microbiol 44:2338-2342

13. Hillemann D, Rusch-Gerdes S, Richter E (2007) Evaluation of the Genotype MTBDRplus assay for rifampin and isoniazid susceptibility testing of Mycobacterium tuberculosis strains and clinical specimens. J Clin Microbiol 45: 2635-2640.

14. Makinen J, Marttila HJ, Marjamaki M, Viljanen MK, Soini H (2006) Comparison of two commercially available DNA line assays for detection of multidrug-resistant Mycobacterium tuberculosis. J Clin Microbiol 44: 350-352.

15. Miotto P, Piana F, Penati V, Canducci F, Migliori GB, et al. (2006) Use of genotype MTBDR assay for molecular detection of rifampin and isoniazid resistance in Mycobacterium tuberculosis clinical strains isolated in Italy. J Clin Microbiol 44: 2485-2491.

16. Vijdea R, Stegger M, Sosnovskaja A, Andersen AB, Thomsen VO, et al. (2008) Multidrug-resistant tuberculosis: Rapid detection off resistance to rifampin and high gold low levels of isoniazid in clinical specimens and isolates. Or J Clin Microbiol Infect Dis 27:1079-1086.

17. Zhuang Y, He X, Zhang X (2000) The studies on the molecular mechanism of rifampin-resistant Mycobacterium tuberculosis. Zhonghua Jie He He Hu Xi Za Zhi 23: 711-714.

18. Thakur C, Umar V, Gupta Ak (2015) Detecting mutation pattern of drugresistant mycobacterium tuberculosis isolates in Himachal pradesh using genotype ( $\left.{ }^{\circ}\right)$ mtbdrplus assay. Indian J Med Microbiol 33: 547-553.

19. Rao S (2009) Patient Tuberculosis and gender: Year analysis and its implications in tuberculosis control. Lung India 26: 46-47.
20. Borgdorff MW, Nagalderke NJ, Dye C, Nunn P (2000) Gender and tuberculosis: A comparison of prevalence surveys with notification data to explore gender differences in case detection. Int J Tuberc Lung Dis 4:123-132.

21. Neyrolles O, Quintana-Murci L (2009) Sexual Inequality in Tuberculosis. PLoS Med 6: E1000199.

22. Mase SR, Ramsay A, Ng V, Henry M (2007) Yield off serial sputum specimen examinations in the diagnosis of pulmonary tuberculosis: systematic review. Int J Tuberc Lung Dis 11: 485-495.

23. Kapata NR, Mbulo G, Cobelens F, De Haas P, Schaap A, et al. (2015) The Second Zambian National Tuberculosis Drug Resistance survey-a comparison of conventional and molecular methods. Trop Med Int Health 20: 1492-1500.

24. Gupta H, Kant S, Jain have, Natu SM, Ahluwalia S (2013) Initial drug resistance pattern among pulmonary tuberculosis patients. Indian J Tuberc. 60: 154-161.

25. Jain NK, Chopra KK, Prasad G (1992) Initial and resistant acquired INH and rifampicin resistant to Mycobacterium tuberculosis and its implication for treatment. Indian J Tuberc 39:180-186.

26. Mahadev B, Jagota P, Srikantaramu NR, Gnaneshwaran M (2003) Surveillance of drug resistance in Mysore district, Karnataka. NTI Bulletin 39: 5-10.

27. Malhotra B, Pathak S, Vyas L, Katoch VM, Srivastava K, et al.(2002) Drug susceptibility profile of Mycobacterium tuberculosis isolates at Jaipur. Indian J Med Microbiol 20: 76-78.

28. Paramasivan CN, Bhaskaran K, Venkataraman P, Chandrasekaran V, Narayanan PR (2000). Surveillance of drug resistance in tuberculosis in the state of Tamil Nadu. Indian J Tuberc 47:27-33.

29. Paramasivan CN, Venkataraman $P$, Chandrasekaran V, Bhat $S$, Narayanan PR (2002) Surveillance of drug resistance tuberculosis in two districts of south India. Int J Tuberc Lung Say 6:479-484.

30. World Health Organization. Total Tuberculosis Carryforward 011

31. Assad HAS M, Alqahtani JM (2012) Primary anti-tuberculous drugs resistance of pulmonary tuberculosis in Southwestern Saudi Arabia. J Infect Public Health 5: 281-285.

32. Banu S, Mahmud HAS M, Rahman MT, Hossain has, Uddin MKM, et al. (2012) Multidrug-Resistant Tuberculosis in Admitted Patients At has Tertiary Referral Hospital of Bangladesh. PLoS One 7: E40545.

33. Menon S, Dharmshale S, Chande C, Gohil have, Lilani S, et al. (2012) Drug resistance profile of Mycobacterium tuberculosis isolates to first line anti-tuberculous drugs: A five years study. Lung India 29:227-231.

34. Abate D, Taye B, Abenso M, Biadgilign S (2012) Epidemiology of antituberculosis drug resistance patterns and trends in tuberculosis referral hospital in Addis Ababa, Ethiopia. BMC Research Notes 5: 462.

35. Ulmasova DJ, Uzakova G, Tillyashayhov MN, Turaev L, van Gemert W, et al. (2013) Multidrug-resistant tuberculosis in Uzbekistan: Results of has nationwide survey, 2010-2011. Euro Surveill 18: Pii: 20609.

36. D'souza DT, Mistry NF, Transfered TS, Dholakia Y, Hoffner S, et al. (2009) High levels of multidrug resistant tuberculosis in new and treatment-failure patients from the Revised National Tuberculosis Control Programme in an urban metropolis (Mumbai) in Wester India. BMC Public Health 9: 211.

37. Mekonnen D, Admassu A, Mulu W, Amor A, Benito A, et al. (2015) Multidrug-resistant and heteroresistant Mycobacterium tuberculosis and associated embarrassment mutations in Ethiopia. Int News Infect Dis 39: 34-38.

38. Desire I, Cyrille B, Florencia D, Souba D, Albert Y, et al. (2014) Molecular diagnosis off resistant Mycobacterium tuberculosis complex to isoniazid and rifampicin in Burkina Faso. The Side medical African newspaper 21: 73.

39. Loïez-Durocher C, Vachée A, Lemaitre N (2000) La Résistance de Mycobacterium tuberculosis aux antituberculeux: méthodes diagnostiques. In Annals of Clinical Biology 58: 291-297. 
Citation: Faye B, Jessika I, Seck MC, Ndour CT, Lamine Gueye PA, et al. (2018) Molecular Evaluation of Resistance to Rifampicin and Isoniazid of Tuberculosis Patients by test “Genotype ${ }^{\circledR}$ MTBDR Plus" in Senegal. J Trop Dis 6: 281. doi:10.4172/2329-891X.1000281

Page 8 of 8

40. Haas WH, Schilke K, Brand J, Amathor B, Weyer, et al. (1997) Molecular analysis of kat $\mathrm{G}$ gene mutations in strains of Mycobacterium tuberculosis complex from Africa. Antimicrob Agents Chemother 41: 1601-1603.

41. Campbell PJ, Morlock GP, Sikes RD, Dalton TL, Metchock B, et al. (2011) Molecular detection of mutations associated with first-and second-line drug resistance compared with conventional drug susceptibility testing off Mycobacterium tuberculosis. Antimicrob Agents Chemother 55: 2032-2041. 